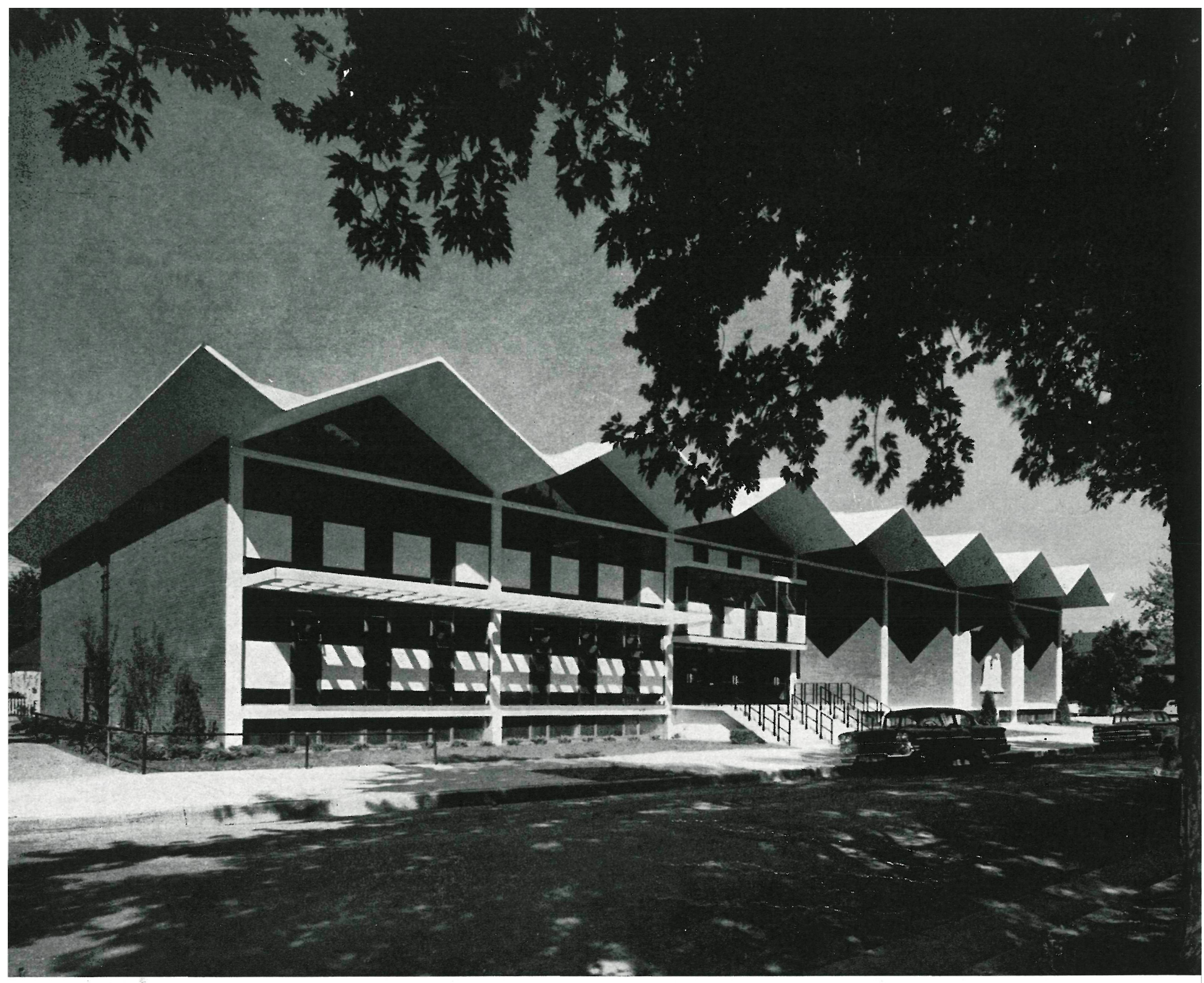

$141 \cdot 55$

escuela de la

\section{sagrada familia}

\section{DENVER Colorado - EE.UU.}

HENRY C. TOLL, arquitecto

El edificio que ahora se ha construído, ampliación de la primitiva escuela de la Sagrada Familia, está situado justamente al otro lado de la calle.

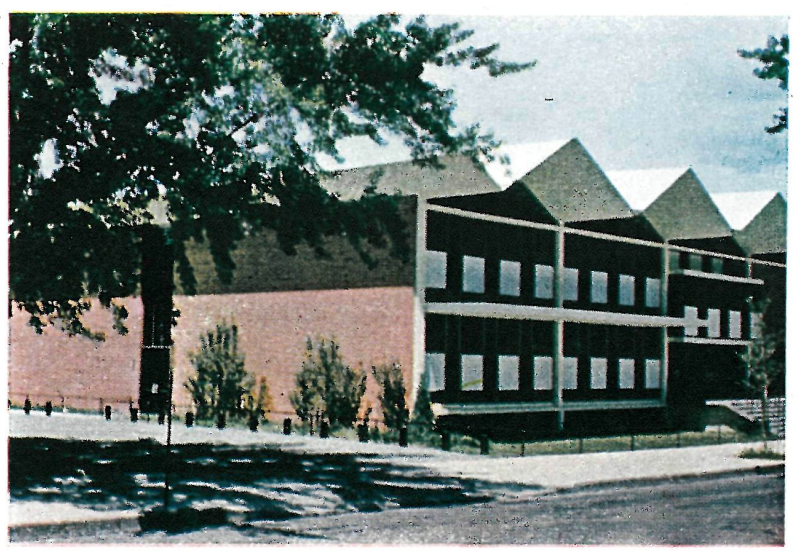


El solar disponible era muy limitado y el programa impuesto muy extenso, ya que incluye las siguientes dependencias: gimnasio, con estrado y 850 plazas sentadas (para representaciones teatrales y actos varios), roperos, duchas y aseos; cafetería capaz para 500 asientos, con la cocina correspondiente; ocho aulas, sala de profesores y aseos; despachos y espacio para almacenes. Fácilmente se deduce que la solución a adoptar habrá de ser muy compacta, tendiendo a un bloque cerrado.

El gimnasio determina la anchura del edificio, pero, como la superficie de aquél es aproximadamente la mitad de la total cubierta, también sirvió este gimnasio de base del sistema estructural, compuesto por una placa plegada de hormigón, solución que fué considerada como la más económica y segura para salvar una luz libre de 26 metros.

Las clases están agrupadas en el extremo sur del edificio y en dos plantas, de modo que la altura total de ambas coincidiera con la que exige el gimnasio.

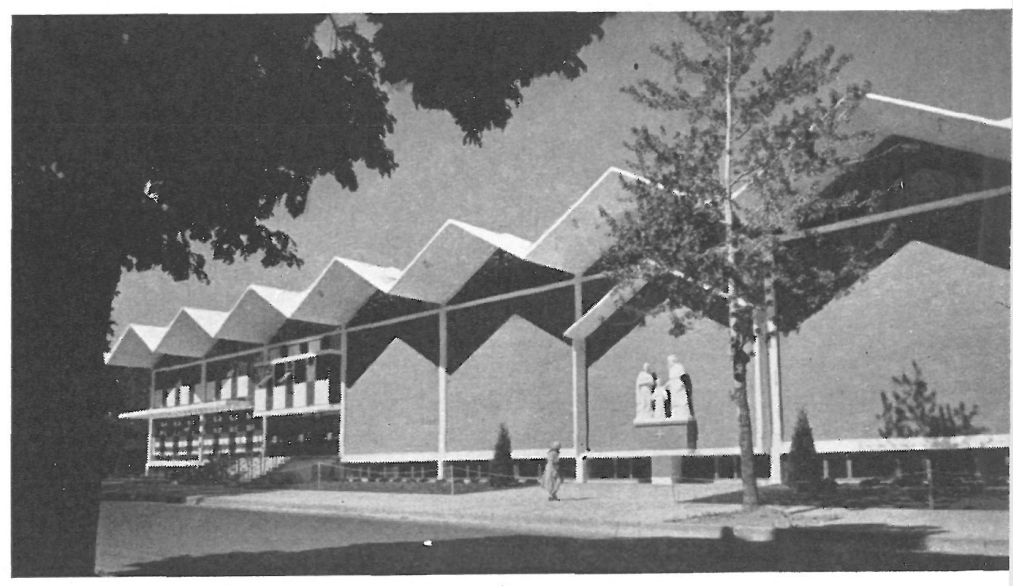

Fachada este.

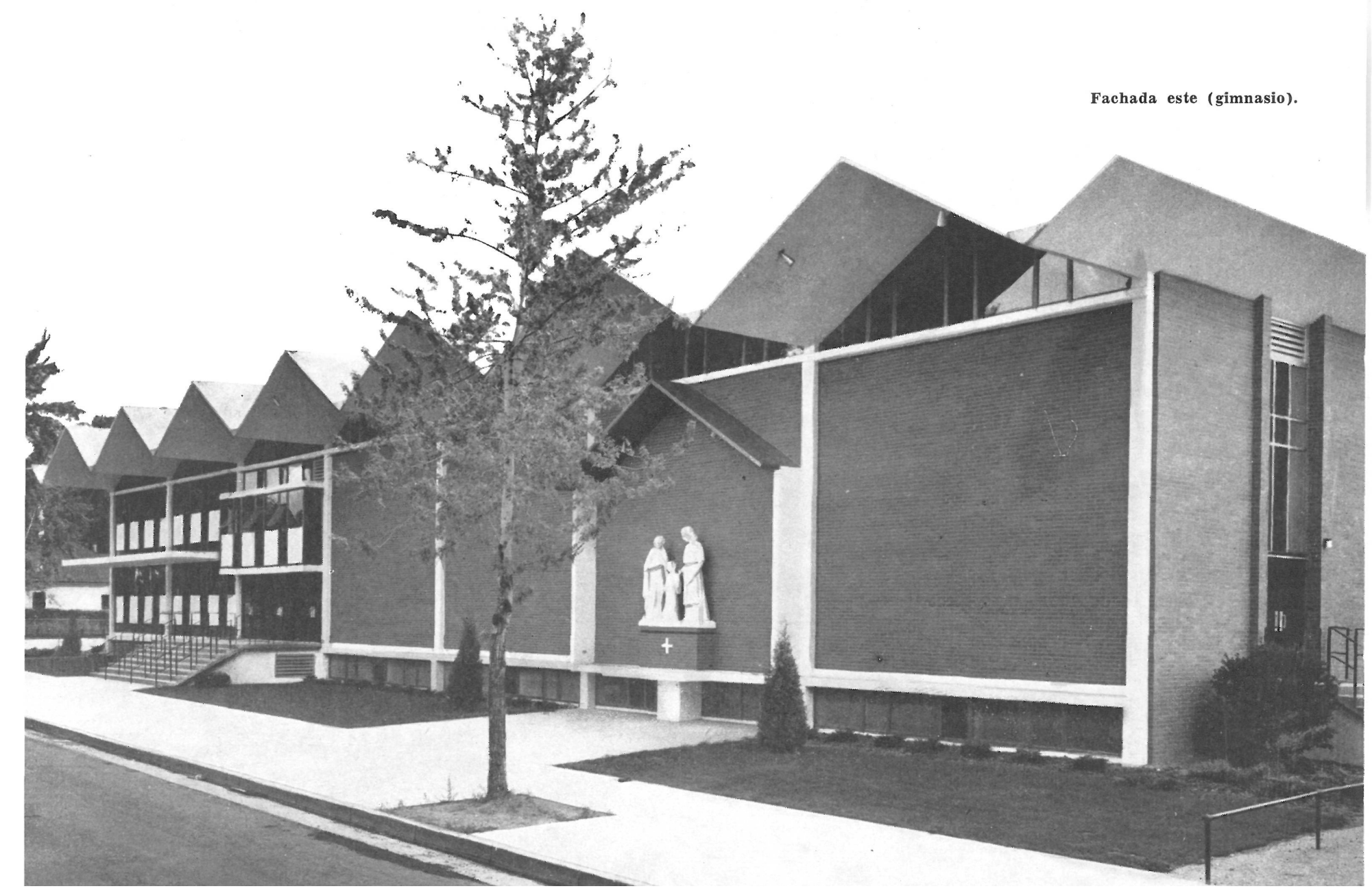




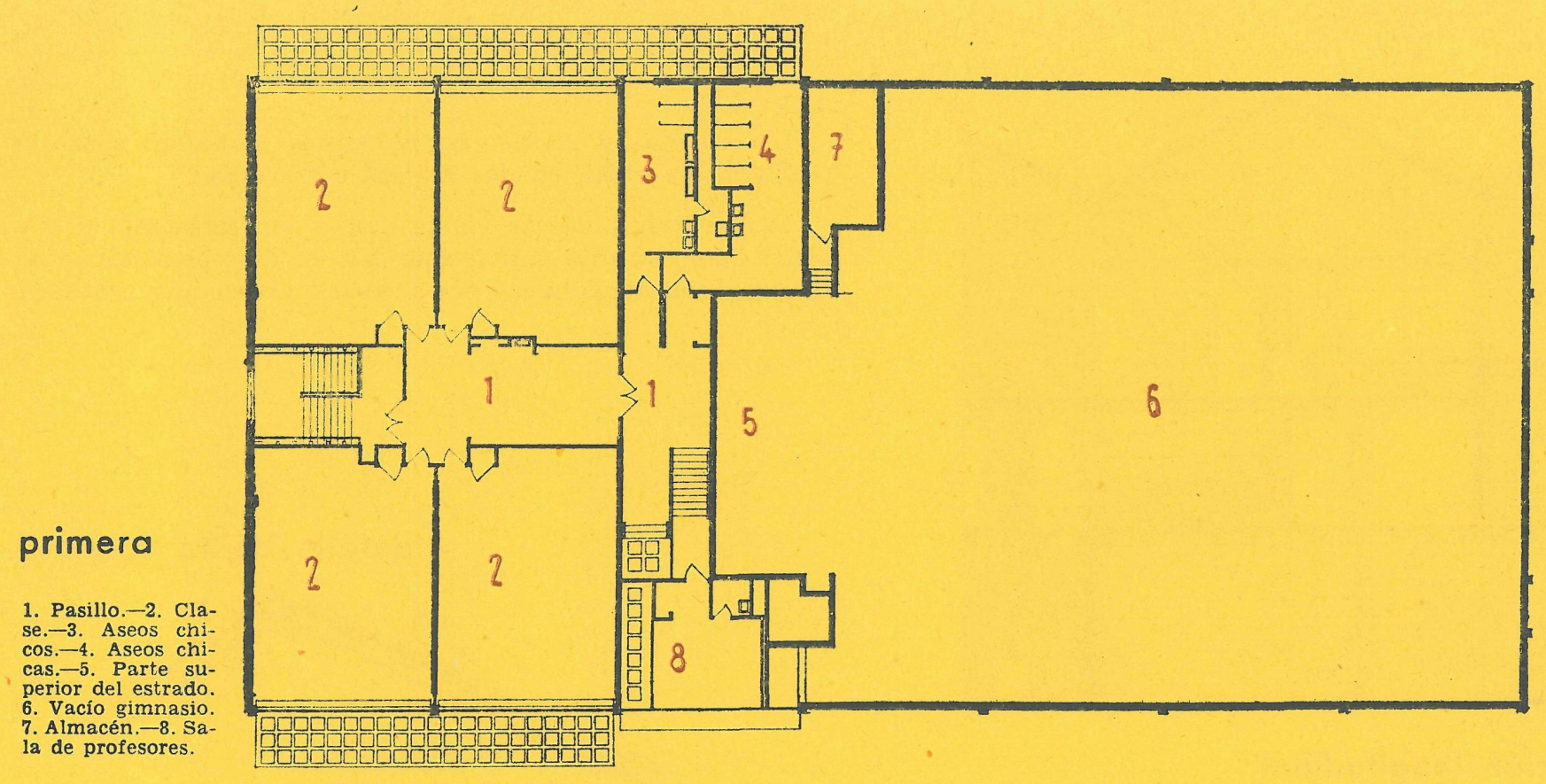

\section{baja \\ 1. Clase.-2. Clase de costura. - 3. Sa- la de ciencias do- mésticas.-4. Pasi- 6. Aseos chicas.- 7. Aseos chicos. 8. Almacén.-9. Es- trado.-10. Gimna- sio.}

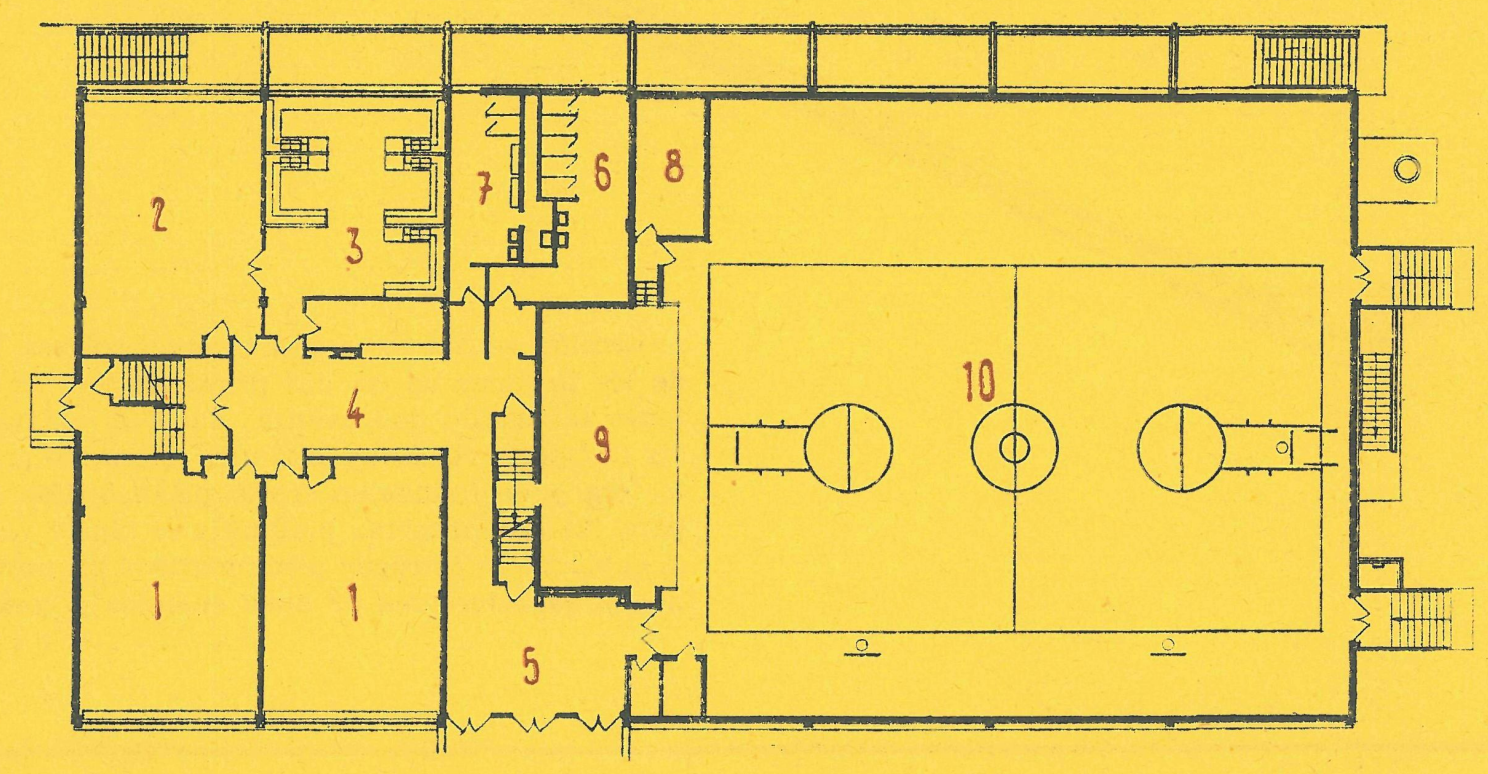

\section{sótanos}

1. Vestuarios de chicos.-2. Pasillo. 3. Vestuario de dad. -5 . Oficina. 6. Cámara oscura. 7. Almacén. - 8 . Aseos chicas. - 9 . Aseos chicos.-10. Conserje.-11. Vestíbulo, - 12 . Sala de utensilio. - 13 Cafeteria.-14. Sala de calderas. 15. Cocina. - 16 Comedor de profesores.-17. Sala de música. - 18 Cuarto de lluvia artificial.

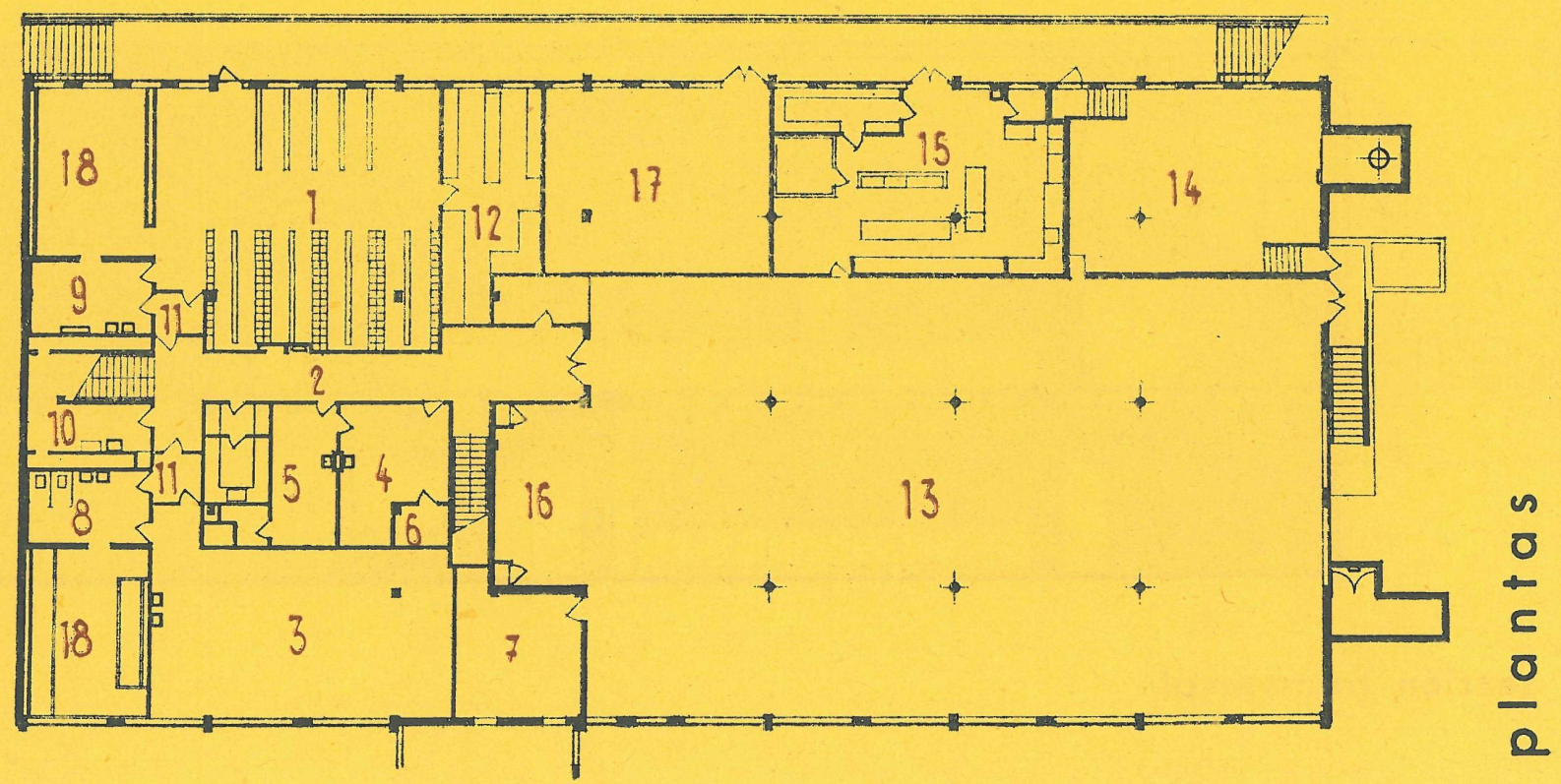




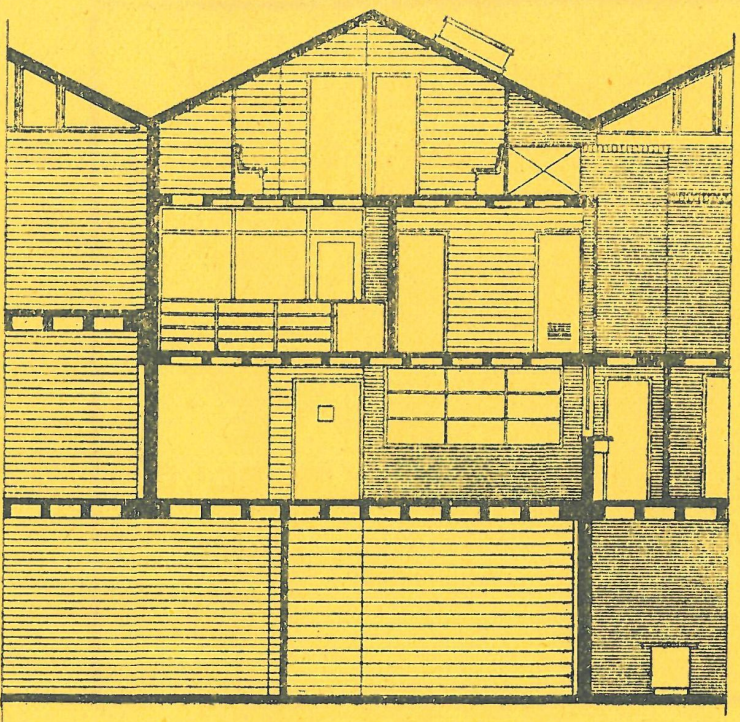

Las oficinas y la sala de profesores se hallan sobre el vestíbulo principal, en dos alturas escalonadas.

Las ventanas de las clases dan a las fachadas este y oeste. Como en esta región abundan los días brillantemente soleados, con pocas nubes, era necesario prever una adecuada

\section{sección longitudinal}

detalle de la cubierta

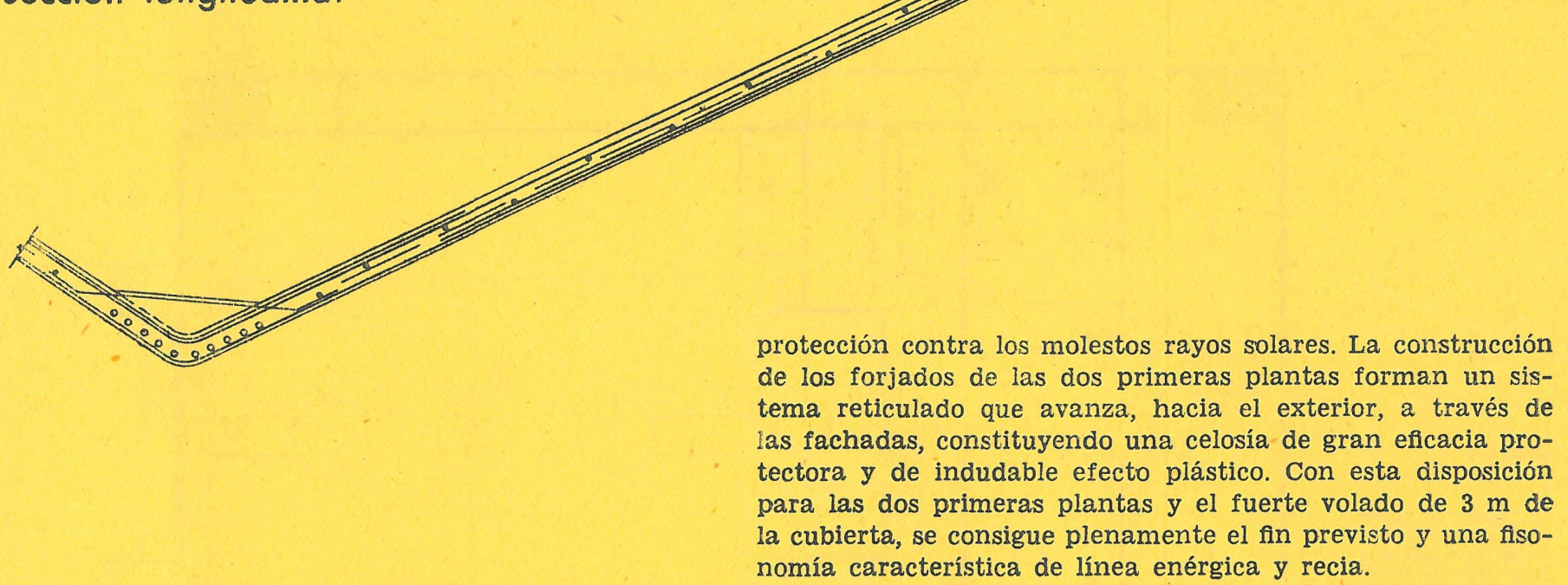
nomía característica de línea enérgica y recia.

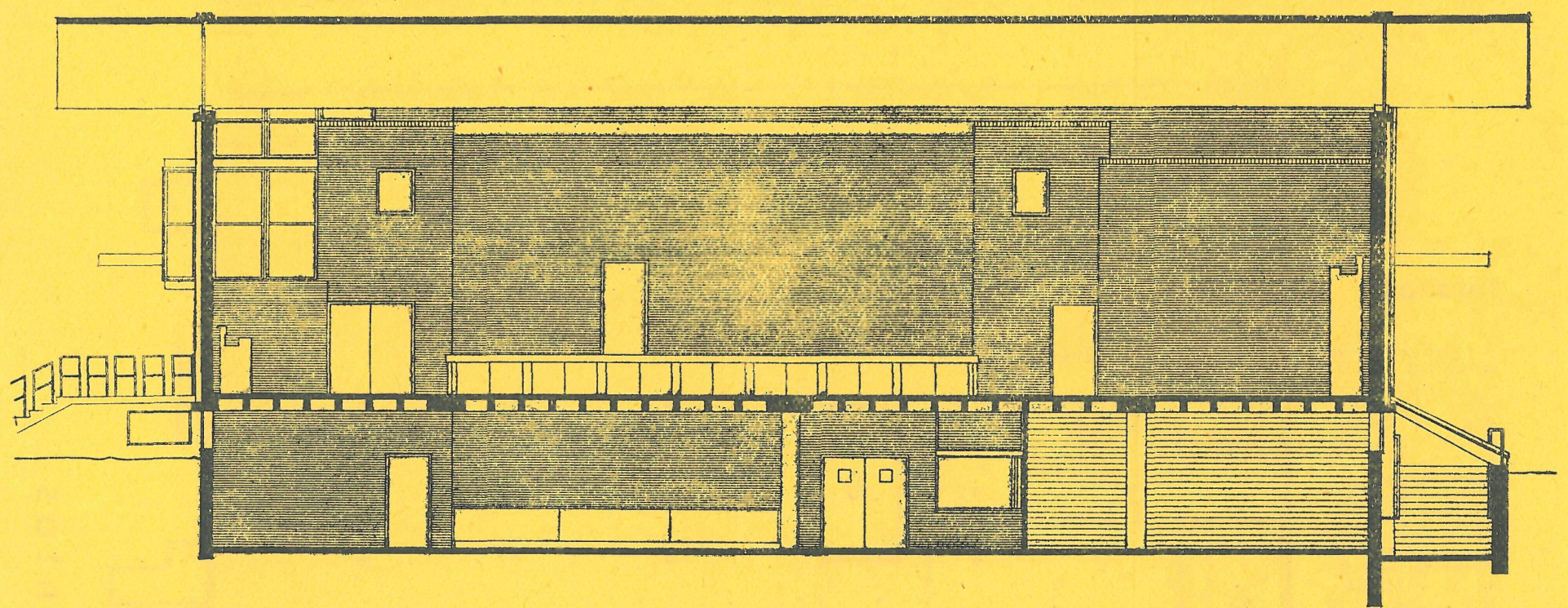

\section{sección transversal}



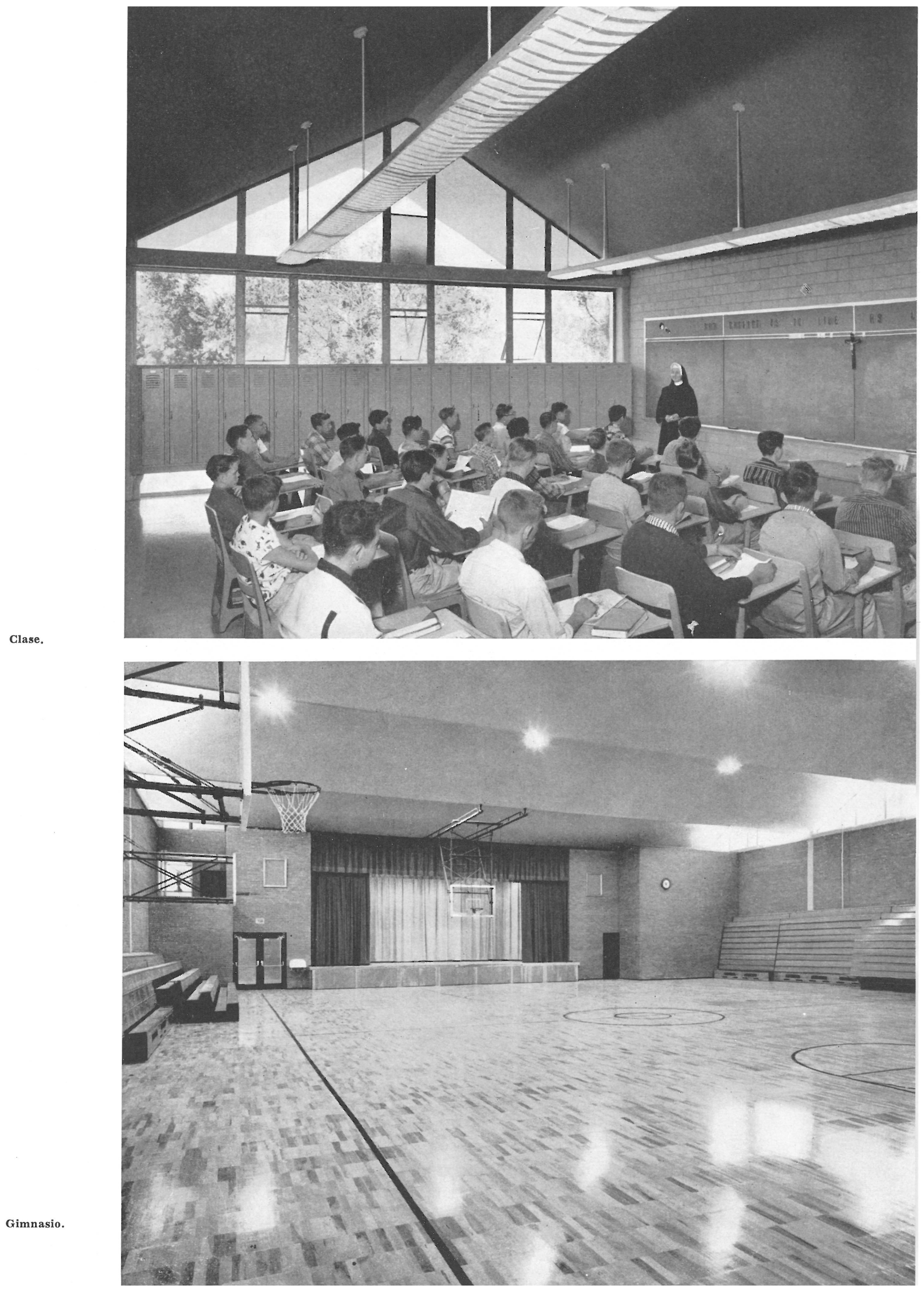
Los cerramientos de las clases son muy vistosos, a base de carpintería metálica, de acero dorado, cristal y paneles esmaltados de porcelana púrpura y blanco. El resto de los paramentos verticales exteriores son de ladrillo visto, acusándose los elementos verticales de hormigón armado con absoluta sinceridad e integridad constructiva.

Los antepechos de las aulas se han colocado muy altos, con el doble objetivo de reducir al mínimo la penetración de los rayos solares y también para evitar que los escolares se distraigan mirando hacia la calle. En cambio, a la altura del suelo, hay una banda de cristal que nos hace el efecto de agrandar la estancia. Entre este hueco bajo y las ventanas altas se ha colocado la batería de armarios roperos, la cual cumple también una misión de sencillo ornato; detrás de ellos hay un estrecho hueco, donde se disponen los convectores de calefacción.

En la fachada principal, sobre un paramento limpio de ladrillo rojo, se destaca, blanco y sencillo, el grupo de la Sagrada Familia, que nos recibe con los brazos abiertos y la mirada dulce.

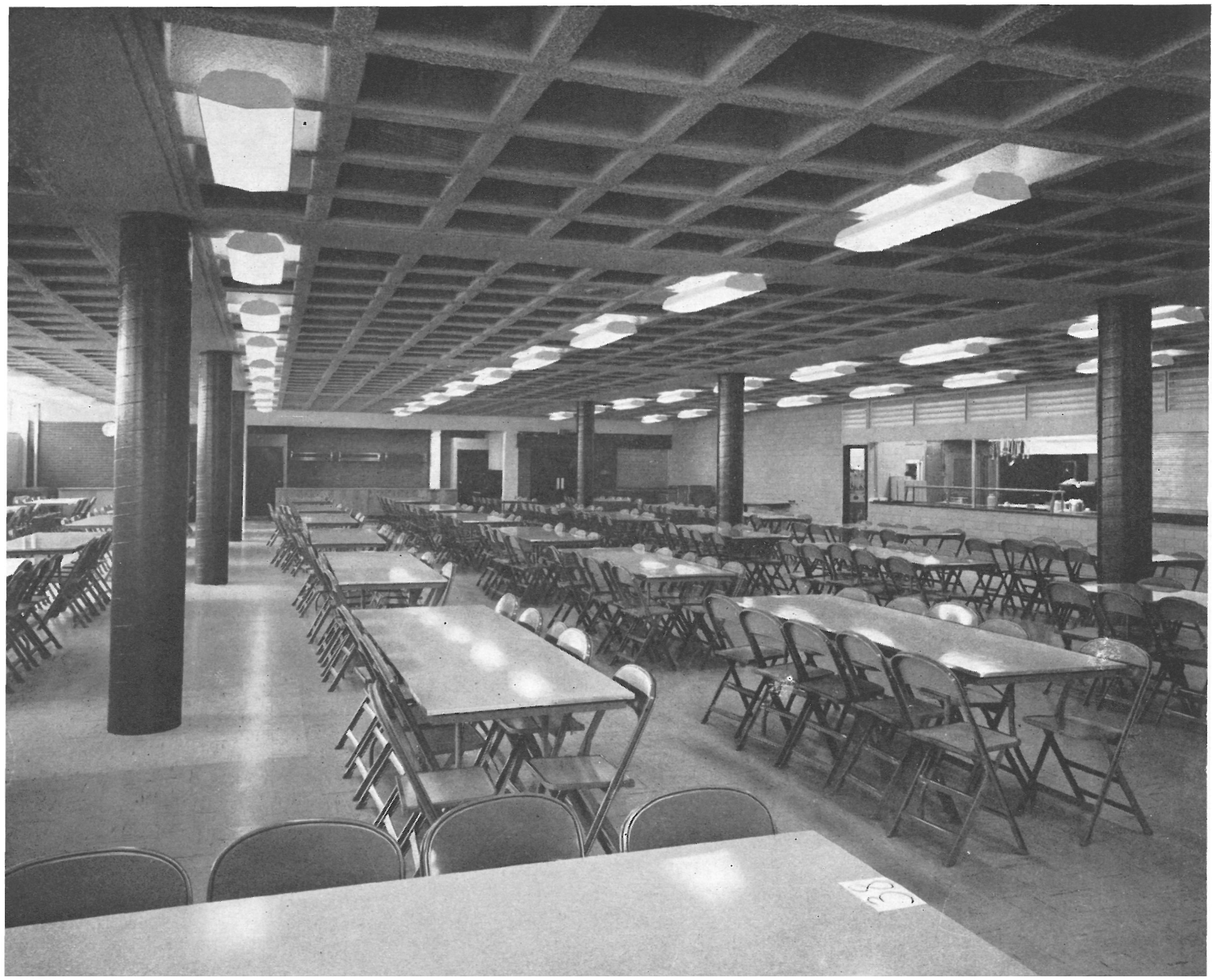

